\title{
Komunikasi Pemasaran dalam Membangun Brand Awareness (Studi Kasus Partipost)
}

\author{
Aileen Belinda, Riris Loisa \\ Aileen.915150103@stu.untar.ac.id,ririsl@fikom.untar.ac.id
}

Fakultas Ilmu Komunikasi Universitas Tarumanagara

\begin{abstract}
Changes in business models are a challenge for business people so they must innovate so that they are not left behind by increasingly digitalized consumers. One effort to build and enhance the company's image in the digital era is brand awareness that requires a continuous effort to build it. The purpose of this study is to find out the marketing that Partipost does in building brand awareness of a brand. The research method used is a descriptive qualitative approach. The study uses depth interviews with three resource persons from two members Partipost and influencers in Partipost. The research data were obtained from interviews, observations, online data and documentation. This study shows that marketing communication used by Partipost in building brand awareness of a brand by using several elements or marketing communication mix that are interrelated will create a form of marketing that is typical by Partipost. The form of marketing used is marketing campaign, which aims to build brand awareness. To find out the success of building brand awareness is determined by the interaction or engagement on marketing that is done.
\end{abstract}

Keywords: Marketing Communication, Marketing Mix, Brand Awareness, Marketing Campaign

\begin{abstract}
Abstrak
Perubahan model bisnis merupakan tantangan bagi para pelaku bisnis sehingga mereka harus berinovasi agar tidak tertinggal oleh konsumen yang semakin terdigitalisasi. Salah satu upaya untuk membangun serta meningkatkan citra perusahaan dalam era digital adalah brand awareness yang memerlukan sebuah usaha yang terus menerus untuk membangunnya. Tujuan penelitian ini mengetahui pemasaran yang digunakan Partipost dalam membangun brand awareness suatu brand. Metode penelitian yang digunakan adalah pendekatan kualitatif secara deskriptif. Penelitian menggunakan wawancara mendalam terhadap tiga orang narasumber yaitu dua orang anggota Partipost dan influencer di Partipost. Data penelitian yang didapat bersumber dari wawancara, data online, observasi dan dokumentasi. Penelitian ini menunjukkan bahwa komunikasi pemasaran yang digunakan Partipost dalam membangun brand awareness suatu brand, dengan menggunakan beberapa unsur atau bauran komunikasi pemasaran yang saling berkaitan, akan menciptakan bentuk pemasaran yang khas oleh Partipost. Bentuk pemasaran yang digunakan adalah marketing campaign, yang bertujuan untuk membangun brand awareness. Untuk mengetahui keberhasilan membangun brand awareness ditentukan dari interaksi atau engagement pada pemasaran yang dilakukan.
\end{abstract}

Kata Kunci: Komunikasi Pemasaran, Bauran Pemasaran, Brand Awareness, Marketing Campaign 


\section{Pendahuluan}

Perkembangan teknologi kini berkembang secara pesat dan berdampak pada berbagai aspek kehidupan. Saat ini semua informasi yang ada dari seluruh dunia dapat dengan mudah tersebar dengan adanya teknologi internet. Era digital yang menghubungkan manusia dengan sistem internet ini memberikan kemudahan dalam penyebaran suatu informasi. Sehingga perubahan teknologi ini mempengaruhi pola hidup atau cara hidup manusia. Menurut penelitian Center of Innovation Policy and Governance (CIPG) tingkat penetrasi internet Indonesia adalah yang tertinggi di Asia dan sudah mencapai $51 \%$.

Salah satu media yang sedang populer digunakan oleh masyarakat luas dalam melakukan interaksi dengan sesamanya adalah media sosial. Media sosial memanfaatkan teknologi internet untuk menghubungkan para penggunanya agar setiap orang dapat terhubung tanpa terbatas oleh ruang dan waktu. Berdasarkan hasil survei WeAreSocial.net dan Hootsuite, diketahui jumlah total pengguna media sosial Instagram mencapai angka 800 juta pada Januari 2018. Pengguna aktif terbanyak di peringkat ketiga adalah Indonesia dengan jumlahnya mencapai 55 juta (Sumber: https://teknologi.id/insight/negara-dengan-jumlah-pengguna-aktif-instagramterbesar/, diakses pada 25 Februari 2019).

Adanya penggunaan internet melalui media sosial tersebut menghadirkan beragam dampak salah satunya adalah bisnis melalui media sosial. Tak hanya lewat situs-situs marketplace, namun media sosial seperti Instagram juga kerap digunakan masyarakat untuk bertransaksi. Meskipun bukan mayoritas, namun peminat perdagangan elektronik atau e-commerce terus meningkat. Perubahan model bisnis juga menjadi tantangan tersendiri bagi para pelaku bisnis. Mereka harus terus berinovasi agar tidak ketinggalan zaman dan tidak ditinggalkan konsumen yang semakin terdigitalisasi.

Salah satu strategi dan upaya untuk membangun serta meningkatkan citra perusahaan dalam era digital adalah peningkatan brand awareness yang memerlukan usaha terus menerus untuk membangunnya. Kesadaran yang tumbuh pada konsumen ini berimplikasi pada keberhasilan sebuah perusahaan agar menjadi pilihan khalayak dan sekaligus mampu memenangkan persaingan bisnis.

Berdasarkan pembahasan di atas maka penulis tertarik untuk membahas munculnya Partipost, yang menjadi salah satu cara pemasaran kepada pemilik bisnis serta solusi untuk membangun brand awarenesss. Tujuan penelitian adalah mengetahui Partipost memanfaatkan unsur pemasaran apa saja untuk membangun brand awareness sebuah perusahaan.

\section{Metode Penelitian}

Penulis menggunakan jenis penelitian kualitatif, menurut Denzin dan Lincoln (dalam Moleong, 2009:5) penelitian kualitatif menggunakan latar ilmiah untuk menafsirkan fenomena yang terjadi serta dilakukan dengan melibatkan berbagai metode. Dalam penelitian kualitatif metode yang biasanya dimanfaatkan adalah wawancara, pengamatan, dan pemanfaatan dokumen. Kemudian penulis menggunakan penelitian kualitatif secara deskriptif. Menurut Gulo (2010:19) dalam 
Aileen Belinda, Riris Loisa: Komunikasi Pemasaran dalam Membangun Brand Awareness (Studi Kasus Partipost)

bukunya berjudul Metodologi Penelitan, penelitian deskriptif merupakan tipe penelitian yang didasarkan pada pertanyaan dasar yaitu 'bagaimana'.

Metode pengumpulan data yang dilakukan oleh penulis dalam penelitian ini adalah studi kasus. Menurut Emzir (2012:20) penelitian studi kasus adalah berusaha untuk menemukan makna, menyelidiki proses, memperoleh pengertian dan pemahaman yang mendalam dari individu, kelompok atau situasi.

Penulis melakukan beberapa teknik dalam pengumpulan data diantaranya adalah wawancara, observasi, dokumentasi, data online dan studi pustaka. Penulis memperoleh data primer dari hasil wawancara secara langsung pada narasumber atau subjek penelitian yakni Chief Operations Officer Head, Implementation Manager dan everyday people influencer di Partipost.

Dalam penelitian ini teknik analisis data yang digunakan, menurut Miles dan Huberman (dalam Herdiansyah, 2010:164) terdiri dari empat tahapan. Mulai dari tahapan pertama yakni tahap pengumpulan data, tahap reduksi data, tahap menampilkan data hingga tahapan keempat adalah tahap kesimpulan atau verifikasi data. Penulis kemudian menggunakan triangulasi sumber, bertujuan menggali kebenaran informasi tertentu melalui berbagai sumber untuk memperoleh data hingga mengetahui adanya alasan terjadinya perbedaan tersebut.

\section{Hasil Temuan dan Diskusi}

Pemasaran menjadi hal penting yang dilakukan setiap produsen dalam memasarkan jasa atau produk kepada masyarakat. Banyaknya kompetitor lain yang mulai muncul menjadi sebuah permasalahan tersendiri bagi suatu produsen untuk dapat unggul di bidangnya masing-masing. Partipost berangkat dari kenyataan bahwa pemasaran menjadi hal utama bagi produsen dalam mempertahankan produk atau jasa yang ditawarkan. Partipost berupaya untuk dapat memecahkan permasalahan yang dimiliki oleh produsen dalam melakukan pemasarannya melalui influencer.

Penulis mengetahui bahwa tujuan Partipost adalah memaksimalkan influencer orang-orang biasa (everyday people influencer--yang disebut sebagai Partiposter, untuk menggunakan kekuatan mulut ke mulut (word of mouth) dalam menyebarluaskan informasi suatu brand. Tujuannya agar dapat mengenalkan, mempengaruhi ataupun menarik perhatian konsumen kepada brand tersebut. Dengan demikian komunikasi pemasaran dapat mempresentasikan gabungan semua unsur dalam bauran pemasaran yang memfasilitasi terjadinya pertukaran dengan menciptakan suatu arti yang disebarluaskan kepada pelanggannya. Penulis kemudian melakukan wawancara dengan key informan dan informan secara langsung untuk mengetahui unsur-unsur pemasaran yang digunakan Partipost dalam memasarkan suatu brand.

Penulis menemukan bahwa Partipost menggunakan enam unsur pemasaran pada pemasarannya yakni periklanan, promosi penjualan, pemasaran langsung, pemasaran via internet, acara dan pengalaman serta berita dari mulut ke mulut. Unsur pemasaran yang pertama adalah periklanan merupakan proses komunikasi massa yang melibatkan sponsor tertentu, pengiklan membayar jasa sebuah media massa atas penyiaran iklannya. Tugas pokoknya adalah mengkomunikasikan informasi seefisien mungkin agar pesan yang disampaikan dapat diterima oleh masyarakat luas (Suhandang, 2010:13). Sesuai dengan teori tersebut Partipost menggunakan unsur pemasaran periklanan pada konten yang diunggah oleh everyday people influencer sebagai perantara untuk memperkenalkan produk atau jasa kepada khalayak. 
Promosi sebagai unsur pemasaran kedua yaitu sebuah sarana komunikasi untuk menarik perhatian dan memberikan informasi produk kepada konsumen. Dapat dipahami bahwa marketing campaign yang dirancang sebagai pemasaran promosi merupakan jawaban Partipost dalam memenuhi unsur pemasaran. Promosi yang ditawarkan oleh brand kepada publik dapat diketahui khalayak melalui unggahan everyday people influencer sehingga dapat mendorong keinginan konsumen untuk membeli produk atau jasa tersebut.

Pemasaran langsung merupakan unsur pemasaran ketiga yang digunakan Partipost, Untuk berkomunikasi secara langsung dapat memanfaatkan penggunaan surat, telepon, faksimili, e-mail dan alat penghubung lainnya. Pemasaran langsung yang digunakan Partipost yakni media sosial sebagai penghubungnya dan everyday people influencer dalam memberikan respon mengenai pengalaman yang dialami pada saat menggunakan produk atau jasa. Sehingga everyday people influencer digambarkan menjadi cerminan konsumen yang bernilai positif, karena dituntut untuk me-market-kan suatu brand dengan baik. Tanggapan dan respon yang bernilai positif berfungsi untuk mempengaruhi pengalaman dan kesan orang-orang di sekitarnya, kemudian dapat membangun brand tersebut.

Acara dan pengalaman disebut sebagai unsur pemasaran keempat dengan tujuan untuk menciptakan kesadaran calon pembeli serta membujuk konsumen untuk membeli produk dan jasa yang dipasarkan perusahaan (Natoradjo, 2011:10). Partipost menggunakan pemasaran acara dan pengalaman suatu brand melalui marketing campaign event attendance. Everyday people influencer wajib datang ke tempat berlangsungnya acara. Penyampaian pesan suatu produk atau jasa dilakukan dengan mengajak konsumen untuk terlibat pada sebuah pemasaran event yang diselenggarakan oleh suatu brand. Dari sudut pandang brand, mereka ini tidak hanya dianggap sebagai influencer yang bekerja sama untuk me-market-kan namun dapat juga menjadi calon konsumen. Setelah terciptanya pengalaman yang berkesan, kemudian everyday people influencer membagikannya melalui media sosial pribadi untuk dapat menceritakan dan menunjukkan kelebihan brand.

Pemasaran via internet menjadi unsur pemasaran kelima, dengan memanfaatkan teknologi yang berbasis digital seperti internet yang mampu bekerja dalam jaringan. Nama Instagram terdiri dari kata "instan-telegram", dengan upaya sederhana yaitu mentransformasikan foto menggunakan beberapa pilihan filter dengan satu klik (Atmoko, 2012:17). Partipost memanfaatkan media sosial Instagram sebagai pilihan utama karena fitur pada Instagram sesuai dengan kebutuhan brand dalam memasarkan produk dan jasanya. Adanya kemudahan untuk mengunggah foto pada Instagram menjadikannya sebagai media sosial yang populer di masyarakat sebagai layanan jejaring sosial berbasis fotografi.

Partipost mengandalkan kekuatan mulut ke mulut sebagai unsur pemasaran adalah awal ide pemasarannya karena diketahui kuat dan berpengaruh. Serta dianggap efektif karena asal kepercayaannya datang dari orang yang tidak mendapatkan keuntungan dari rekomendasi mereka. Terlihat pada ungkapan oleh narasumber bahwa penerapan word of mouth dari rekomendasi teman memberikan hasil 92\% lebih berpengaruh dibandingkan metode pemasaran pada umumnya. Pengalaman pembelian yang dimiliki oleh teman dapat menjadi rekomendasi dan berpengaruh karena adanya faktor kepercayaan kepada teman dan umumnya akan berpendapat jujur sesuai dengan pengalaman yang dialaminya. Konsumen sudah mulai bosan dengan pemasaran tersebut, dan seiring canggih dan murahnya teknologi, siapa pun kini dapat membuat konten berkualitas dan menyebarkannya. 
Aileen Belinda, Riris Loisa: Komunikasi Pemasaran dalam Membangun Brand Awareness (Studi Kasus Partipost)

Partipost memanfaatkan jaringan influencer dengan pertumbuhan tercepat di Asia. Hingga kini jumlah everyday people influencer yang sudah mengunduh sebanyak empat puluh lima ribu (45.000).

Partipost bersama dengan pihak brand melaksanakan marketing campaign dalam memenuhi unsur-unsur bauran pemasaran. Marketing campaign dapat disesuaikan periode waktu dan tujuan masing-masing brand yang ingin dicapai. Pernyataan tersebut sejalan dengan teori Rogers dan Storey (Venus,2012) bahwa kampanye adalah serangkaian tindakan komunikasi terencana dengan tujuan menciptakan efek tertentu pada sejumlah besar khalayak yang dilakukan secara berkelanjutan pada kurun waktu tertentu.

Salah satu campaign yang bekerja sama dengan Partipost adalah brand fashion lokal Third Day Co. Pada data terlihat periode waktu campaign yang dilakukan, yakni waktu registrasi Partiposter selama satu bulan dan hampir bersamaan dengan waktu unggahan konten. Syaratnya adalah Partiposter yang memiliki minimal 2,000 followers, ketentuan untuk fotonya yaitu dengan menggenakan baju Third Day Co, sedangkan caption-nya berupa penjelasan (review dan testimonial) baju dan menggunakan hashtag (SIMPLEDOESIT, TDPEOPLE, Thirddaycamo dan thirddayco).

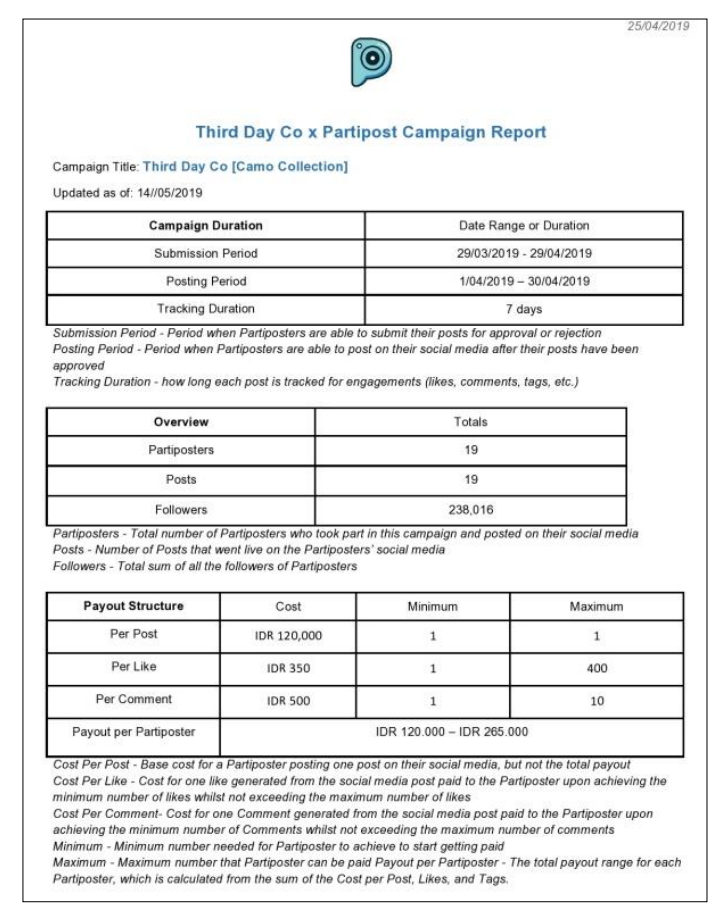

Gambar 1. Campaign Report Partipost x Third Day Co Sumber: Dokumentasi Peneliti (2019)

Reward yang diberikan saat post di Instagram adalah Rp 120.000, per-like diberi Rp 350 dengan maksimal hitungannya sebanyak 400 likes dan per-comment akan diberi Rp 500 dengan batas maksimal hitungan sebanyak 10 comments. Sehingga perkiraan reward yang didapat oleh Partiposter antara Rp 120.000 - Rp 265.000 .

Jumlah Partiposter yang melaksanakan campaign tersebut yakni sebanyak 19 orang dengan jumlah followersnya 238,016. Total likes yang diperoleh sebanyak 
14.728, comments sebanyak 902, mentions sebanyak 24 dan jumlah engagement yang didapat sebesar $7.56 \%$.

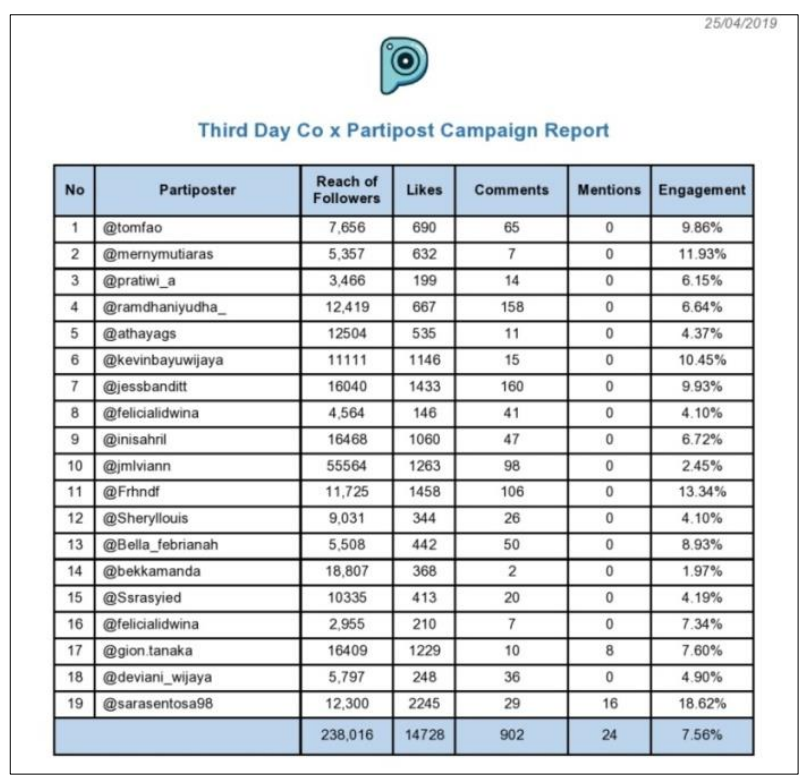

Gambar 2. Campaign Report Engagement Partipost x Third Day Co Sumber: Dokumentasi Peneliti (2019)

Pengukuran brand awareness Third Day Co, dilihat dari besarnya engagement. Pada campaign ini, dapat dikatakan sukses karena pihak brand melakukan campaign ulang bersama dengan Partipost.

Brand awareness yang dibangun oleh Partipost melalui kampanye pemasaran. Keberhasilan dalam membangun brand awareness yakni dengan mengamati engagement atau interaksi terhadap konten akun yang dikelola. Interaksi dapat dilihat dari like, comment, mention dan follower konten yang bersangkutan. Pernyataan tersebut diperkuat dari Jason Falls, pada artikel tentang engagement di media sosial pada tahun 2012, bahwa hasil komunikasi yang baik adalah apabila audiens memberikan perhatian atau respon.

Penulis mengetahui Partipost mewujudkan unsur komunikasi pemasaran ke dalam bentuk kampanye pemasaran sehingga dapat membangun brand awareness bagi produk atau jasa suatu brand.

Perbandingan hasil penelitian yang penulis teliti mengenai "Komunikasi Pemasaran dalam Membangun Brand Awareness" dengan judul penelitian "Analisis Bauran Komunikasi Pemasaran Publisher Manikmaya Dalam Mempromosikan Board Game Pada Tahun 2015" oleh Bachtiar Mujaddidi dan Idola Perdini Putri.

Kedua penelitian ini saling menggunakan bauran atau unsur komunikasi pemasaran untuk memasarkan suatu produk atau jasa. Penulis menggunakan enam unsur pemasaran dari teori Hermawan (2012) bauran atau unsur pemasaran dalam menciptakan pengaruh pada konsumen, bahwa komunikasi pemasaran yang baik dalam pelaksaannya akan berdampak pada perspektif positif atau kepercayaan terhadap merek yang disampaikan. Sedangkan Bachtiar Mujaddidi dan Idola Perdini Putri menggunakan teori Kotler \& Armstrong, bauran komunikasi pemasaran perusahaan merupakan paduan dari periklanan, promosi penjualan, hubungan 
Aileen Belinda, Riris Loisa: Komunikasi Pemasaran dalam Membangun Brand Awareness (Studi Kasus Partipost)

masyarakat, penjualan personal, dan pemasaran langsung untuk digunakan perusahaan mengkomunikasikan nilai pelanggan secara persuasif dan membangun hubungan dengan pelanggan. Teori-teori tersebut menimbulkan efek yang berbeda, pada teori Hermawan penulis melaksanakan pemasaran untuk mendapatkan nilai yang positif dan memunculkan kepercayaan konsumen pada suatu brand. Tujuan ini berbeda dengan Bachtiar Mujaddidi dan Idola Perdini Putri menurut teori Kotler \& Armstrong bahwa keinginannya luas yakni membangun hubungan secara persuasif.

Hasil dari penelitian Bachtiar Mujaddidi dan Idola Perdini Putri adalah manikmaya melakukan kegiatan bauran komunikasi yang saling berkaitan dengan yang lain seperti melakukan membuka pre-order untuk acara launching produk baru dengan memberi keuntungan lebih dibandingkan dengan membeli retail. Penelitian tersebut hampir serupa dengan penulis, karena bauran atau unsur komunikasi yang digunakan saling berhubungan namun memberikan bentuk pemasaran lain. Melalui kampanye pemasaran untuk mendapatkan perhatian dari mata publik.

\section{Simpulan}

Penulis menunjukkan beberapa kesimpulan yang menjadi hasil dari penelitian komunikasi pemasaran yang dilakukan Partipost dengan menggunakan unsur atau bauran komunikasi pemasaran. Unsur pemasaran yang digunakan Partipost adalah periklanan, promosi penjualan, pemasaran langsung, pemasaran via internet, acara dan pengalaman dan berita dari mulut ke mulut.

Dari beberapa unsur komunikasi pemasaran yang digunakan terbukti saling berkaitan antara satu dengan lainnya. Everyday people influencer sebagai pemasaran langsung mengkomunikasikan pesan yang brand ingin sampaikan berupa promosi dan pengalaman melalui konten pada media sosial Instagram yang disebut sebagai iklan dan pemasaran dilakukan melalui internet. Pada konten tersebut menciptakan pengaruh mulut ke mulut yang kuat antara everyday people influencer dengan pengikutnya. Unsur pemasaran yang berhubungan tersebut didasari dari bentuk pemasaran yang digunakan Partipost yaitu marketing campaign (kampanye pemasaran). Marketing campaign yang dilakukan bertujuan untuk membangun brand awareness suatu brand selanjutnya keberhasilan dapat terlihat pada interaksi publik akan suatu konten (engagement).

\section{Ucapan Terima Kasih}

Penulis mengucapkan terima kasih kepada seluruh narasumber, yaitu pihakpihak dari Partipost Indonesia yaitu ka Ben, ka Chiro dan Syerly yang telah dan dapat meluangkan waktu untuk memberi informasi yang dibutuhkan selama proses pengumpulan data dalam penelitian ini.

\section{Daftar Pustaka}

Atmoko, Bambang Dwi. 2012. Instagram Handbook. Jakarta: Media Kita.

Bachtiar Mujaddidi dan Idola Perdini Putri. (2018). Analisis Bauran Komunikasi Pemasaran Publisher Manikmaya Dalam Mempromosikan Board Game Pada Tahun 2015. Jurnal Komunikasi Bisnis. Vol.5, No.3, pp. 4006-4010

Emzir. 2012. Metodologi Penelitian Kualitatif: Analisis Data. Jakarta: Raja Grafindo Persada 
Gulo, W. 2010. Metodologi Penelitian. Jakarta: Grasindo.

Herdiansyah, Haris. 2010. Metode Penelitian Kualitatif untuk Ilmu-ilmu Sosial. Jakarta: Salemba Humanika.

Laksmi, AA \& Oktafani. (2017). Pengaruh Electronic Word of Mouth Terhadap Minat Beli Followers Instagram Pada Warunk Upnormal. Jurnal Computech \& Bisnis. Vol.10, No.2

Moleong, Lexy J. 2009. Metode Penelitian Kualitatif. Bandung: Remaja Rosdakarya

Natoradjo, Sulyus. 2011 .Event organizing: Dasar-dasar event management. Jakarta: Kompas Gramedia.

https://teknologi.id/insight/negara-dengan-jumlah-pengguna-aktif-instagramterbesar/

Suhandang, Kustadi. 2010. Periklanan: Manajemen, Kiat, dan Strategi. Bandung: Nuansa.

Venus, A. (2012). Manajemen kampanye. Bandung: Simbiosa Rekatama Media 